\title{
Economic and Financial Transactions Govern Business Cycles
}

\author{
Victor Olkhov* \\ TVEL, Moscow, Russia
}

\author{
Article history: \\ Received: \\ $23 / 10 / 2018$ \\ Revised: \\ Accepted: \\ $09 / 01 / 2019$ \\ Published:

Abstract

Problem/Relevance - This paper presents new description of the business cycles that for decades remain as relevant and important economic problem.

Research Objective/Questions - We propose that econometrics can provide sufficient data for assessments of risk ratings for almost all economic agents. We use risk ratings as coordinates of agents and show that the business cycles are consequences of collective change of risk coordinates of agents and their financial variables.

Methodology - We aggregate similar financial variables of agents and define macro variables as functions on economic space. Economic and financial transactions between agents are the only tools that change their extensive variables. We aggregate similar transactions between agents with risk coordinates $\mathbf{x}$ and $\mathbf{y}$ and define macro transactions as functions of $\mathbf{x}$ and $\mathbf{y}$. We derive economic equations that describe evolution of macro transactions and hence describe evolution of macro variables.

Major Findings - As example we study simple model that describes interactions between Credits transactions from Creditors at $\mathbf{x}$ to Borrowers at $\mathbf{y}$ and Loan-Repayment transactions that describe refunds from Borrowers at $\mathbf{y}$ to Creditors at $\mathbf{x}$. We show that collective motions of Creditors and Borrowers from safer to risky area and back on economic space induce frequencies of macroeconomic Credit cycles.

Implications - Our model can improve forecasting of the business cycles and help increase economic sustainability and financial policy-making. That requires development of risk ratings methodologies and corporate accounting procedures that should correspond each other to enable risk assessments of economic agents.

Keywords: business cycle, economic transactions, risk assessment, economic space

\section{Introduction}

Financial accounting and reporting are important tools for corporate management and for macroeconomic modelling. In this paper we show that risk ratings assessments mostly based on financial accounting and reporting of corporations, banks, small firms and companies establish ground for macroeconomic modelling of the business cycles. Assessments of risk ratings of economic agents utilize data delivered by accounting and reporting of numerous economic agents in different industries of the entire economics. Change of risk ratings of agents induce change of

\footnotetext{
* Corresponding author.

E-Mail address: victor.olkhov@gmail.com

ORCID: 0000-0003-0944-5113
} 
their economic state and financial activity and as we show in this paper ultimately define Investment and Credit cycles, Consumption and Demand cycles and etc.

Business cycles are the heart of macroeconomic evolution and are studied for decades. "Serious efforts to explain business crises and depressions began amid the violent fluctuations in trade which followed the Napoleonic Wars" (Mitchell, 1927). Not much changed since Mitchell statement nearly a century ago. Description of business cycles remains essential macroeconomic problem: Tinbergen (1935), Schumpeter (1939), Smithies (1957), Morgenstern, (1959), Lucas (1980), Kydland \& Prescott (1982), Plosser, (1989), Zarnowitz (1992), Lucas (1995), Diebold \& Rudebusch, 1999; Rebelo (2005), Kiyotaki (2011), Schmitt-Grohé \& Uribe (2012), Diebold \& Yilmaz, 2013; Jorda, Schularick \& Taylor (2016), Bordalo, Gennaioli \& Shleifer (2016). "The incorporation of cyclical phenomena into the system of economic equilibrium with which they are in apparent contradiction remains the crucial problem of Trade Cycle Theory" (Hayek, 1933, quoted by Lucas, 1976). "Why aggregate variables undergo repeated fluctuations about trend, all of essentially the same character? Prior to Keynes' General Theory, the resolution of this question was regarded as one of the main outstanding challenges to economic research, and attempts to meet this challenge were called business cycle theory" (Lucas, 1995).

Risk assessments play a special role for the business cycle studies (Tallarini, 2000; Pesaran, Schuermann \& Treutler, 2007; Mendoza \& Yue, 2012; Diebold, 2012). Risks affect macroeconomic and finance development and stability (Huang, Zhou \& Zhu, 2009; Nicolò \& Lucchetta, 2011) and pricing models (Bollerslev \& Zhang, 2003). Endogenous business cycle models within general equilibrium framework (Grandmont, 1985; Farmer \& Woodford, 1997; Bilbiie, Ghironi \& Melitz, 2012; Growiec, McAdam \& Mućk, 2015; Engle, 2017) and relations between risks and business cycles counts hundreds of publications (Alvarez \& Jermann, 1999; Tallarini, 2000; Pesaran, Schuermann \& Treutler, 2007; Christiano, Motto \& Rostagno, 2013). Actually current business cycle models follow general economic equilibrium framework (Lucas, 1975; Kydland \& Prescott, 1982; 1991; Mullineux \& Dickinson, 1992; Kiyotaki, 2011; Mendoza \& Yue, 2012). "The real business cycle theory is a business cycle application of the Arrow-Debreu model, which is the standard general equilibrium theory of market economies." (Kiyotaki 2011). Simply speaking business cycles are treated as transitions from one equilibrium state to another.

Actually permanent economic development increases complexity of economic and financial relations and induces changes in origin and behavior of business cycles. The increasing complexities and diversities of the business cycles require new approaches for their modelling. With this in mind on base of econometrics and assessments of risk ratings of economic agents we develop the business cycles model that doesn't use general equilibrium framework. Let's assume that econometrics provide sufficient data to assess risks ratings for almost all agents of entire economics and estimate amount of economic and financial transactions between agents. We show that economic and financial transactions between agents allow describe macroeconomic evolution and model the business cycles.

Description of transactions between all economic agents is a very complex problem. To simplify it we rougher the model and aggregate transactions between agents with same risk ratings. We replace description of transactions between separate agents with ratings $\boldsymbol{x}$ and $\boldsymbol{y}$ by description of transactions between all agents with ratings $\boldsymbol{x}$ and $\boldsymbol{y}$. We model evolution of transactions by economic equations (see below (4.1-4.2) and (5.1-5.7)) and show that business cycles are consequences of these equations.

As example of our general approach we describe a model of Credits transactions between agents. Aggregates of Credit transactions from all Creditors with risk ratings $\boldsymbol{x}$ to all Borrowers with risk ratings $\boldsymbol{y}$ define macro Credits transactions $C L(t, \boldsymbol{x}, \boldsymbol{y})$ as function of time and $\boldsymbol{x}$ and $\boldsymbol{y}$. We derive economic equations that govern evolution of Credit transactions and show why and how they describe Credit cycles of entire economics. 
The rest of the paper is organized as follows. In Section 2 we present model setup and main definitions (Olkhov, 2017b-2017e). In Section 3 we introduce economic equations on macrotransactions and discuss their economic meaning. In Section 4 we argue economic assumptions that allow describe the business cycles. As example we study a model interactions between Credits transactions $C L(t, \boldsymbol{x}, \boldsymbol{y})$ from Creditors at with risk ratings $\boldsymbol{x}$ to Borrowers with risk ratings $\boldsymbol{y}$ and Loans-Repayments transactions $L R(t, \boldsymbol{x}, \boldsymbol{y})$ of refunds from Borrowers at $\boldsymbol{y}$ to Creditors at $\boldsymbol{x}$. We model these transactions by a system of economic equations and describe their evolution in a selfconsistent manner. Starting with these equations we derive the system of ordinary differential equations (ODE) and derive simple solutions that describe the business cycles around the growth trend of Credits $C(t)$ in the entire economics. Conclusions are in Section 5.

\section{Model Setup}

In this Section we introduce main definitions of our approach (Olkhov, 2016a-b; 2017a-c). Let's regard any participants of economic and financial relations like banks, companies, households and etc., as economic agents. Agents have a lot of economic and financial variables like Assets, Credits, Consumption, Debts and Investment and etc. Aggregations of agents variables define macroeconomic variables. For example aggregation of agents Investment equals macro Investment, aggregation of agents Consumption defines macro Consumption and etc. Thus description of agents variables model evolution of macro variables like Investment, Credits, Working Hours and etc., and different properties of business cycles. Economic and financial variables of agents are changed due to corresponding transactions between agents. For example Banks provide Credits to Borrowers and such transactions change amount of Credits provided by Banks and amount of Loans received by Borrowers. Hence description of transactions between agents models evolution of agents variables. Thus modelling transactions helps model the business cycles.

It is obvious that any transactions between agents are performed under definite Expectations. Since Muth (1961) and Lucas (1972) importance and impact of Expectations on economic and financial evolution were studied in numerous papers and we refer (Kydland \& Prescott, 1980; Brunnermeier \& Parker, 2005; Greenwood \& Shleifer, 2014; Manski, 2017) as only small part of these research. Macroeconomic evolution is very complex and any model of macroeconomics describes certain approximation only. In our paper we simplify description of the business cycles and neglect impact of Expectations on transactions between agents. Let's propose that transactions between agents depend on other transactions only. Such approximation allows describe transactions-driven business cycle model. We shall model impact of Expectations on transactions and the business cycles in forthcoming publications.

Let's regard macroeconomics as ensemble of numerous economic agents that are under action of different risks. There are many economic and financial risks that impact agents variables and their transactions. Impacts of different risks on agents economic evolution and risk assessment are studied by numerous of papers and we refer only few (Gupton, et al, 1997; Alvarez \& Jermann, 1999; Diebold, 2012; Christiano et al, 2013; BIS, 2014; Skoglund \& Chen, 2015; Engle, 2017). We don't argue here problems of risk assessments but show that risk assessment methodologies can become a ground for macroeconomic modelling. Let's outline that for decades international rating companies as Moody's, Fitch, S\&P (Metz \& Cantor, 2007; Chane-Kon, et.al, 2010; Kraemer \& Vazza, 2012) provide risk assessment and attribute risk ratings like $A A A, A, B B$, $C$ and etc. for global banks and international corporations. Let's propose that it is possible to assess risk ratings for all agents of entire economics -for global banks, corporations and for small companies and even households. That requires a lot of additional econometric and statistical data. We hope that quality, accuracy and granularity of current U.S. National Income and Product 
Accounts system (Fox, et al., 2014) give us confidence that all econometric problems can be solved. Let's propose that our assumptions are fulfilled and it is possible evaluate risk assessments for all agents of entire economics. Risk ratings take values of risk grades like $A A A, A, B B, C$ and we regard these grades as points $x_{1}, \ldots x_{m}$ of discrete space. Usage of risks ratings allows distribute economic agents over points $x_{1}, \ldots x_{m}$ on discrete space. Let's further call the space that maps agents by their risk ratings as economic space. Ratings of single risk distribute agents over points of onedimensional discrete space. Assessments of two or three risks distribute agents on economic space with dimension two or three. It is obvious that number of risk grades, number of points $A A A, A$, $B B, C \ldots$ is determined by methodology of risk assessment. Let's assume that assessment methodology can be generalized to make risk grades continuous so, they fill certain interval $(0, X)$ on space $R$. Let's take point 0 as most secure and point $X$ as most risky grades. Value of most risky grade $X$ always can be set as $X=1$ but we use $X$ notation for convenience. Let's assume that risk assessments of $n$ risks define coordinates of agents on space $R^{n}$. Economic agents of economics under $n$ risks fill economic domain (1.1):

$$
0 \leq x_{i} \leq X_{i} ; i=1, \ldots n
$$

Below we study economic and financial transactions and develop the business cycle model for economics that is under the action of $n$ risks on economic space $R^{n}$.

Transactions between agents change their economic and financial variables. For example agent $A$ can provide Credits to agent $B$. This transaction will change Credits provided by agent $\mathrm{A}$ and Loans received by agent $B$. Each transaction takes certain time $d t$ and we consider transactions as rate or speed of change of corresponding variables. For example Credits transactions from agent $A$ at moment $t$ define rate of change of total Credits provided by agent $A$ at moment $t$. Let's call extensive economic or financial variables of two agents as mutual if output of one becomes an input of the other. For example, Credits as output of Creditors are mutual to Loans as input of Borrowers. Any exchange between agents by mutual variables is carried out by corresponding transactions. Any agent at point $\boldsymbol{x}$ may carry out transactions with agent at any point $\boldsymbol{y}$ on economic space. Different transactions define evolution of different couples of mutual variables. We regard agents as simple units of macroeconomics and treat agents alike to "economic particles" and economic or financial transactions between agents as "economic interactions" between "economic particles". For brevity let's further call economic agents as e-particles and economic space as e-space. Now let's present above considerations in a more formal manner.

As example let's study Credits transactions that provide Loans from Creditors to Borrowers and follow Olkhov (2017b-c). Let's take that Credits transactions $c_{1,2}(t, \boldsymbol{x}, \boldsymbol{y})$ describe Credits provided by from e-particle 1 as Creditor at point $\boldsymbol{x}$ to Borrower at e-particle 2 as at point $\boldsymbol{y}$ at moment $t$. Let's call Credits and Loans as mutual variables. Let's state that all extensive economic or financial variables can be allocated as pairs of mutual variables or can be describes by mutual variables. Thus transactions describe dynamics of all extensive economic and financial variables of e-particles and hence determine macroeconomic evolution and the business cycles.

\section{Macro transactions between points on e-space}

Let's assume that transactions between e-particles at $\boldsymbol{x}$ and $\boldsymbol{y}$ describe exchange of mutual variables like Credits and Loans. Description of transactions between separate e-particles is very complex problem and we replace it by rougher model. To do that let's define economic and financial transactions between points of e-space. Main idea: let's replace precise description of transactions between separate e-particles by rougher description of transactions associated with points of espace that don't distinguish separate e-particles. Such a roughening is already used in economics. 
For example aggregation of all Credits between agents of entire economics define macro Credit $C(t)$ (see 3.2) provided in macroeconomics at moment $t$ and equal macro Loans $L(t)$ received in macroeconomics at moment $t$. Modelling transactions between all separate agents at points $\boldsymbol{x}$ and $\boldsymbol{y}$ on e-space establish too detailed picture. On the other hand description of variables like macro Credits $C(t)$ as aggregates all transactions between all agents of entire economics gives too simplified economic model. We develop intermediate description of economy that aggregate transactions between agents that belong to domains near points $\boldsymbol{x}$ and $\boldsymbol{y}$ on risk e-space. Such approximation neglect granularity of separate e-particles but allows take into account distribution of transactions on e-space. Such approach is similar to transition from kinetic description of multiparticles system to hydrodynamic approximation in physics (Landau \& Lifshitz, 1981; 1987; Resibois \& De Leener, 1977).

Let's assume that e-particles on e-space $R^{n}$ at moment $t$ have coordinates $x=\left(x_{1}, \ldots x_{n}\right)$ and risk velocities $\boldsymbol{v}=\left(v_{1}, \ldots v_{n}\right)$. Risk velocities describe change of risk coordinates of e-particles. Let's rougher description of Credit transactions between e-particles by small unit volume $d V(z)$ and replace it by transactions between points of e-space. Let's assume that

$$
d V(\boldsymbol{z})=d V(\boldsymbol{x}) d V(\boldsymbol{y}) ; \quad \boldsymbol{z}=(\boldsymbol{x}, \boldsymbol{y})
$$

Let's assume that a unit volume $d V(\boldsymbol{x})$ at $\boldsymbol{x}$ and $d V(\boldsymbol{y})$ at $\boldsymbol{y}$ contains many e-particles (agents) but scales $d V_{i}$ of a unit volume $d V(\boldsymbol{x})$ are small to compare with scales $X_{i}$ of economic domain (1.1):

$$
d V_{i} \ll X_{i}, i=1, \ldots n ; d V(\boldsymbol{x})=\prod_{i=1, . . n} d V_{i}
$$

Let's define Credit transaction $C L(t, \boldsymbol{z})$ at point $\boldsymbol{z}=(\boldsymbol{x}, \boldsymbol{y})$ as sum of all Credit transactions $c l_{1,2}(t, \boldsymbol{x}, \boldsymbol{y})$ between all e-particles $i=1, . . N(\boldsymbol{x})$ in unit volume $d V(\boldsymbol{x})$ at $\boldsymbol{x}$ and $j=1, . . N(\boldsymbol{y})$ in unit volume $d V(\boldsymbol{y})$ at $\boldsymbol{y}$ and average this sum during time term $\Delta$ as follows:

$$
\begin{array}{r}
C L(t, \boldsymbol{z})=\sum_{i \in d V(\boldsymbol{x}) ; j \in d V(\boldsymbol{y}) ; \Delta} c l_{i, j}(t, \boldsymbol{x}, \boldsymbol{y}) \\
\sum_{i \in d V(\boldsymbol{x}) ; j \in d V(\boldsymbol{y}) ; \Delta} c l_{i, j}(t, \boldsymbol{x}, \boldsymbol{y})=\frac{1}{\Delta} \int_{t}^{t+\Delta} d \tau \sum_{i \in d V(\boldsymbol{x}) ; j \in d V} c l_{i, j}(t, \boldsymbol{x}, \boldsymbol{y})
\end{array}
$$

We use $i \in d V(\boldsymbol{x})$ to denote that coordinates $\boldsymbol{x}$ of e-particle $i$ belong to unit volume $d V(\boldsymbol{x})$. Let's underline that value of Credit transaction $C L(t, z)$ at $z=(x, y)$ can change in time and due to motion of e-particles at $\boldsymbol{x}$ and $\boldsymbol{y}$. Motion of e-particles at $\boldsymbol{x}$ and $\boldsymbol{y}$ induce motion of Credit transaction $C L(t, z)$ alike to motion of continuous media and we outline parallels between Credit transaction $C L(t, z)$ and fluids. To define motion or velocity $\boldsymbol{v}(t, \boldsymbol{x}, \boldsymbol{y})$ of Credit transaction let's introduce impulse $\boldsymbol{p}_{i j}$ of Credit transaction $c_{1,2}(t, \boldsymbol{x}, \boldsymbol{y})$ for couple of e-particles $i$ and $j$ at $\boldsymbol{x}$ and $\boldsymbol{y}$ that are involved into on $2 n$-dimensional e-space $z=(x, y)$ respectively as

$$
\begin{aligned}
& \boldsymbol{p}_{i j}(t, \mathbf{z})=\left(\boldsymbol{p}_{\boldsymbol{x} i j}(t, \mathbf{z}), \boldsymbol{p}_{\boldsymbol{y} i j}(t, \mathbf{z})\right) ; \boldsymbol{z}=(\boldsymbol{x}, \boldsymbol{y}) \\
& \boldsymbol{p}_{\boldsymbol{x} i j}(t, \boldsymbol{z})=c l_{i, j}(t, \boldsymbol{x}, \boldsymbol{y}) \boldsymbol{v}_{i}(\boldsymbol{x}) \quad ; \quad \boldsymbol{p}_{\boldsymbol{y} i j}(t, \boldsymbol{z})=c l_{i, j}(t, \boldsymbol{x}, \boldsymbol{y}) \boldsymbol{v}_{j}(\boldsymbol{y})
\end{aligned}
$$

Then define impulse of Credit transactions $C L(t, z)$ as:

$$
\begin{aligned}
& \boldsymbol{P}(t, \mathbf{z})=\left(\boldsymbol{P}_{\boldsymbol{x}}(t, \mathbf{z}), \boldsymbol{P}_{\boldsymbol{y}}(t, \mathbf{z})\right) \\
& \boldsymbol{P}_{\boldsymbol{x}}(t, \boldsymbol{z})=\sum_{i \in d V(\boldsymbol{x}) ; j \in d V(\boldsymbol{y}) \Delta} \boldsymbol{p}_{\boldsymbol{x} i j}(t, \boldsymbol{x}, \boldsymbol{y})=\sum_{i \in d V(\boldsymbol{x}) ; j \in d V(\boldsymbol{y}) \Delta} c l_{i, j}(t, \boldsymbol{x}, \boldsymbol{y}) \boldsymbol{v}_{i}(\boldsymbol{x}) \\
& \boldsymbol{P}_{\boldsymbol{x}}(t, \boldsymbol{z})=\sum_{i \in d V(\boldsymbol{x}) ; j \in d V(\boldsymbol{y}) \Delta} \boldsymbol{p}_{\boldsymbol{y} i j}(t, \boldsymbol{x}, \boldsymbol{y})=\sum_{i \in d V(\boldsymbol{x}) ; j \in d V(\boldsymbol{y}) \Delta} c l_{i, j}(t, \boldsymbol{x}, \boldsymbol{y}) \boldsymbol{v}_{j}(\boldsymbol{y})
\end{aligned}
$$


Relations $(2.6 ; 2.7)$ define velocity $\boldsymbol{v}(t, \boldsymbol{x}, \boldsymbol{y})$ of transaction $C L(t, z)$ as:

$$
\begin{array}{r}
\boldsymbol{P}(t, \boldsymbol{x}, \boldsymbol{y})=\boldsymbol{v}(t, \boldsymbol{x}, \boldsymbol{y}) C L(t, \boldsymbol{x}, \boldsymbol{y}) ; \boldsymbol{v}(t, \mathbf{z})=\left(\boldsymbol{v}_{\boldsymbol{x}}(t, \mathbf{z}) ; \boldsymbol{v}_{\boldsymbol{y}}(t, \mathbf{z})\right) \\
\boldsymbol{P}_{\boldsymbol{x}}(t, \mathbf{z})=\boldsymbol{v}_{\boldsymbol{x}}(t, \mathbf{z}) C L(t, \mathbf{z}) \quad ; \quad \boldsymbol{P}_{\boldsymbol{y}}(t, \mathbf{z})=\boldsymbol{v}_{\boldsymbol{y}}(t, \mathbf{z}) C L(t, \mathbf{z})
\end{array}
$$

Relations (1.4; 2.1-2.7) define Credit transactions $C L(t, z)$ and impulse $\boldsymbol{P}(t, \boldsymbol{z})$ on $2 n$-dimensional espace $z=(\boldsymbol{x}, \boldsymbol{y})$. Integral of Credits transactions $C L(t, \boldsymbol{x}, \boldsymbol{y})$ by variable $\boldsymbol{y}$ over e-space $R^{n}$ defines rate of change all of Credits $C(t, x)$ from point $x$ at moment $t$.

$$
C(t, \boldsymbol{x})=\int d \boldsymbol{y} C L(t, \boldsymbol{x}, \boldsymbol{y}) ; L(t, \boldsymbol{y})=\int d \boldsymbol{x} C L(t, \boldsymbol{x}, \boldsymbol{y})
$$

Integral (3.1) also defines rate of change of all Loans $L(t, \boldsymbol{y})$ received at point $\boldsymbol{y}$. Integral of $C L(t, \boldsymbol{x}, \boldsymbol{y})$ by variables $\boldsymbol{x}$ and $\boldsymbol{y}$ on e-space describes rate of change of total Credits $C(t)$ provided in economy and total Loans $L(t)$ received in economy at time $t$ :

$$
C(t)=\int d \boldsymbol{x} C(t, \boldsymbol{x})=\int d \boldsymbol{x} d \boldsymbol{y} C L(t, \boldsymbol{x}, \boldsymbol{y})=\int d \boldsymbol{y} L(t, \boldsymbol{y})=L(t)
$$

Relations $(3.1 ; 3.2)$ show that Credits transactions $C L(t, x, y)$ define evolution of Credits $C(t, x)$ provided from point $\boldsymbol{x}$ and total Credits $C(t)$ provided in economy at moment $t$ and their mutual variables - Loans $L(t, \boldsymbol{y})$ received at point $\boldsymbol{y}$ and total Loans $L(t)$ received in macroeconomics at moment $t$.

As usual risk ratings are related with economic agents or their securities. Now let's introduce notion of mean risk for macroeconomic or financial variable. As example let's take macro Credits and Loans. Let's assume that e-particle 1 (Bank 1) with risk coordinate $x$ at moment $t$ issues Credits $C_{1}(t, \boldsymbol{x})$ and e-particle 2 (Bank 2) with risk coordinate $\boldsymbol{y}$ at moment $t$ issues Credits $C_{2}(t, \boldsymbol{y})$. Coordinate $\boldsymbol{x}$ and $\boldsymbol{y}$ define risk ratings of Bank1 (e-particle1) and Bank 2 (e-particle 2). Let's state a question: What is the risk rating for group of two Banks? Group of two Banks issue Credits $C_{1}(t, \boldsymbol{x})+C_{2}(t, \boldsymbol{y})$. Let's define mean Credits risk $\boldsymbol{X}_{C l, 2}(t)$ for two Banks as:

$$
\boldsymbol{X}_{C 1,2}(t)=\frac{x C_{1}(t, \boldsymbol{x})+\boldsymbol{y} C_{2}(t, \boldsymbol{y})}{C_{1}(t, \boldsymbol{x})+C_{2}(t, \boldsymbol{y})} \text { or } \boldsymbol{X}_{C 1,2}(t)\left(C_{1}(t, \boldsymbol{x})+C_{2}(t, \boldsymbol{y})\right)=\boldsymbol{x} C_{1}(t, \boldsymbol{x})+\boldsymbol{y} C_{2}(t, \boldsymbol{y})
$$

Relations (3.3) define mean risk of Credits as average of risk coordinates of agents weighted by value of Credits they issue at time $t$. Similar relations for Loans $L_{1}(t, \boldsymbol{x})$ and $L_{2}(t, \boldsymbol{y})$ received by eparticles 1 and 2 at points $\boldsymbol{x}$ and $\boldsymbol{y}$ define Loans mean risk $\boldsymbol{X}_{L 1,2}(t)$ as:

$$
\boldsymbol{X}_{L 1,2}(t)\left(L_{1}(t, \boldsymbol{x})+L_{2}(t, \boldsymbol{y})\right)=\boldsymbol{x} L_{1}(t, \boldsymbol{x})+\boldsymbol{y} L_{2}(t, \boldsymbol{y})
$$

Thus different variables as Credits $C(t, \boldsymbol{x})$ and Loans $L(t, \boldsymbol{x})$ determine different values of mean risk coordinates $\boldsymbol{X}_{C 1,2}(t)$ and $\boldsymbol{X}_{L 1,2}(t)$ respectively. Relations (3.3) are alike to center of Credits mass $\boldsymbol{X}_{C 1,2}(t)$ of two physical particles with mass $C_{1}(t, \boldsymbol{x})$ at $\boldsymbol{x}$ and mass $C_{2}(t, \boldsymbol{y})$ at $\boldsymbol{y}$. Let's define Credits mean risk coordinates $\boldsymbol{X}_{C}(t)$ similar to relations (3.3) as integral over economic domain (1.1) taking into account total Credits $C(t)(3.2)$ :

$$
\boldsymbol{X}_{C}(t) C(t)=\int d \boldsymbol{x} \quad \boldsymbol{x} C(t, \boldsymbol{x})=\int d \boldsymbol{x} d \boldsymbol{y} \boldsymbol{x} C L(t, \boldsymbol{x}, \boldsymbol{y})
$$

and mean Loan risk coordinates $\boldsymbol{X}_{L}(t)$ as

$$
\boldsymbol{X}_{L}(t) L(t)=\int d \boldsymbol{y} \boldsymbol{y} L(t, \boldsymbol{y})=\int d \boldsymbol{x} d \boldsymbol{y} \boldsymbol{y} C L(t, \boldsymbol{x}, \boldsymbol{y})
$$


Mean Credits risk $\boldsymbol{X}_{C}(t)$ equals mean risks of total Credits $C(t)$ issued in economy. It is alike to coordinates $\boldsymbol{X}_{C}(t)$ of center of total "mass" of Credits $C(t)$ in economy with Credits mass density $C(t, x)$. Let's remind that $C(t, x)$ - amount of Credits provided from all agents at point $\boldsymbol{x}$. Mean Loans risk $\boldsymbol{X}_{L}(t)$ defines mean risk coordinates of total Loans $L(t)$ received in economy. Nevertheless that due to (3.2) total Credits $C(t)$ equal total Loans $L(t)$ mean Credits risk $\boldsymbol{X}_{C}(t)$ is not equal to mean Loans risk $\boldsymbol{X}_{L}(t)$. Different economic variables - Investment $I(t, \boldsymbol{x})$, Assets $A(t, \boldsymbol{x})$ and etc. define different values of their mean risks. Let's remind that all variables are determined by corresponding economic transactions due to relations (3.1). Credits transactions mean risk of $C L(t, z=(x, y))$ define mean risk of mutual variables for $z=(x, y)$ as:

$$
\left\{\boldsymbol{X}_{C}(t) C(t) ; L(t) \boldsymbol{X}_{L}(t)\right\}=\left\{\int d \boldsymbol{x} d \boldsymbol{y} \boldsymbol{x} C L(t, \boldsymbol{x}, \boldsymbol{y}) ; \int d \boldsymbol{x} d \boldsymbol{y} \boldsymbol{y} C L(t, \boldsymbol{x}, \boldsymbol{y})\right\}
$$

Relations (3.5) show that macro transactions like Credits transactions $C L(t, \boldsymbol{x}, \boldsymbol{y})$ determine evolution of Credits mean risks $\boldsymbol{X}_{C}(t)$ and Loans mean risks $\boldsymbol{X}_{L}(t)$. The same statement is correct for mean risks determined by other macro transactions.

Why we attract attention to definition of mean risks of macro variables? We propose that evolutions of mean risks for different macro variables impact the business cycles of these variables. Let's take Credits $C(t)$ as example. Mean Credits risk $\boldsymbol{X}_{C}(t)$ is not a constant. It changes due to change of coordinates $\boldsymbol{x}$ and amount of Credits provided by e-particles. Growth of risks of eparticles can increase and decline of risks can reduce mean Credits risk $\boldsymbol{X}_{C}(t)$. E-particles fill economic domain (1.1). Risk ratings of e-particles on economic domain (1.1) are bounded by minimum or most secure and maximum or most risky grades. Thus mean Credits risk $\boldsymbol{X}_{C}(t)$ as well as mean risks of any other macro variable can't grow up or diminish steadily along each risk axes as their values are bounded on economic domain (1.1). Hence value of mean Credits risk $\boldsymbol{X}_{C}(t)$ should oscillate along risk axes and these fluctuations of mean risk $\boldsymbol{X}_{C}(t)$ can be very complex.

We propose that business cycles and fluctuations of mean risks of macro variables are highly associated. Growth of mean Credits risk $X_{C}(t)$ correspond with growth of total Credits $\mathrm{C}(t)$ provided in economy and decline of Credits mean risk correspond with total Credits contraction. Reasons for mean risk change can be exogenous or endogenous. Mean risk change can be induced by technology shocks, political or regulatory decisions and etc. Reasons can be different but outcome should be the same - business cycles are governed by change of mean risks. Relations between mean Credits risk $\boldsymbol{X}_{C}(t)$ and value of total Credits $C(t)$ are much more complex but we repeat main statement: business cycles and fluctuations of mean risks are linked very tightly. To avoid excess complexity we don't derive equations on mean risks here, but refer to (Olkhov, 2017d).

As we show in (3.5) Credits transaction $C L(t, \boldsymbol{x}, \boldsymbol{y})$ determine mean Credits $\boldsymbol{X}_{C}(t)$ and Loans $\boldsymbol{X}_{L}(t)$ risks. Below in Sec. 3, Sec.4 and in Appendix we introduce economic equations that describe model dynamics of Credits transaction $C L(t, \boldsymbol{x}, \boldsymbol{y})$ on e-space (5.1-5.5). Starting with these equations we derive the system of ODE (A.4; A.8.4-7; A.10.1-10.2) that describe the business cycles of macro Credits $C(t)$ provided in economy and macro Loans $L(t)$ received in economy. Due to (3.1) total value of Credits $M C(t, x)$ provided from point $\boldsymbol{x}$ up to moment $t$ equal:

$$
\frac{\partial}{\partial t} M C(t, \boldsymbol{x})=C(t, \boldsymbol{x}) ; \quad M C(t, \boldsymbol{x})=M C(0, \boldsymbol{x})+\int_{0}^{t} d \tau \int d \boldsymbol{y} C L(\tau, \boldsymbol{x}, \boldsymbol{y})
$$

Total value of Loans $M L(t, y)$ received at point $\boldsymbol{y}$ up to moment $t$

$$
\frac{\partial}{\partial t} M L(t, \boldsymbol{x})=L(t, \boldsymbol{x}) \quad ; M L(t, \boldsymbol{y})=M L(0, \boldsymbol{y})+\int_{0}^{t} d \tau \int d \boldsymbol{x} C L(\tau, \boldsymbol{x}, \boldsymbol{y})
$$


Here $M C(0, x)$ define initial values of Credits issued from point $\boldsymbol{x}$ on e-space. Relations similar to (3.1 - 3.9) define evolution and fluctuations of all extensive economic and financial variables determined by macro transactions. Aggregate Credits $M C(t)$ issued in entire economics equal (see $3.2 ; 3.8)$ :

$$
M C(t)=M C(0)+\int_{0}^{t} d \tau \int d \boldsymbol{x} d \boldsymbol{y} C L(\tau, \boldsymbol{x}, \boldsymbol{y})=M C(0)+\int_{0}^{t} d \tau C(\tau)
$$

Thus description of Business or Credit cycles of $M C(t)$ should model rate of change of total Credits $C(t)$ and Credits transactions $C L(t, \boldsymbol{x}, \boldsymbol{y})(3.11)$ :

$$
\frac{d}{d t} M C(t)=C(t)=\int d \boldsymbol{x} d \boldsymbol{y} C L(t, \boldsymbol{x}, \boldsymbol{y})
$$

Oscillations of rate of change of Credits $C(t)$ define the Credit cycles $M C(t)$. Relations (3.1-3.11) establish basis for modelling the business cycles of economic and financial variables via description of macro transaction. Below as example we derive economic equations that describe evolution of Credit transactions $C L(t, \boldsymbol{x}, \boldsymbol{y})$.

\section{Economic equations on macro transactions}

Credit transactions between points $\boldsymbol{x}$ and $\boldsymbol{y}$ on e-space determine evolution of macro variables (3.1 - 3.11) (Olkhov, 2017b; 2017c). Value of Credits transactions $C L(t, z),(1.4)$ in a unit volume $d V$ at point $\boldsymbol{z}=(\boldsymbol{x}, \boldsymbol{y})$ can change due to two factors. First factor describes change of $C L(t, z)$ in time as $\partial C L / \partial t$. Second factor describes change of $C L(t, z)$ in a unit volume $d V$ due to flux of transactions flow $\boldsymbol{v} C L$ through surface of a unit volume. Divergence theorem (Strauss 2008, p.179) states that surface integral of flux $v C L$ through surface of a unit volume $d V$ equals volume integral of divergence $\boldsymbol{v} C L$. Thus total change of transaction $C L(t, z)$ in a unit volume $d V$ equals

$$
\frac{\partial C L}{\partial t}+\nabla \cdot(\boldsymbol{v} C L)
$$

Here $\boldsymbol{v}=\left(\boldsymbol{v}_{X}, \boldsymbol{v}_{Y}\right)$ - velocity of transaction $C L(t, \boldsymbol{z})$ on $2 n$-dimension e-space $R^{2 n} \boldsymbol{z}=(\boldsymbol{x}, \boldsymbol{y})$ determined by (2.1-2.7), bold letters $\boldsymbol{x}, \boldsymbol{y}, \boldsymbol{z}, \boldsymbol{P}, \boldsymbol{Q}_{2}$ mean vectors, roman $t, C L$ mean scalars and divergence equals:

$$
\nabla \cdot(\boldsymbol{v} C L)=\sum_{i=1, \ldots n} \frac{\partial}{\partial x_{i}}\left(v_{x i}(t, \boldsymbol{x}, \boldsymbol{y}) C L(t, \boldsymbol{x}, \boldsymbol{y})\right)+\sum_{i=1, \ldots n} \frac{\partial}{\partial y_{i}}\left(v_{y i}(t, \boldsymbol{x}, \boldsymbol{y}) C L(t, \boldsymbol{x}, \boldsymbol{y})\right)
$$

Let's denote other factors that change of transactions $C L(t, z)$ in a unit volume as $Q_{1}$. Then equation on Credits transactions $C L(t, z)$ takes form:

$$
\frac{\partial C L}{\partial t}+\nabla \cdot(v C L)=Q_{1}
$$

Equation (4.1) is a simple balance of factors that change $C L(t, z)$. Left side (4.1) describes changes of $C L(t, z)$ in a unit volume - due to change in time and due to flux through surface of a unit volume. Right side describes action of other factors like macro variables or other transactions. The same reasons define equations on transactions impulses $\boldsymbol{P}(t, \boldsymbol{z})=\left(\boldsymbol{P}_{\boldsymbol{x}}(t, \boldsymbol{z}) \boldsymbol{P}_{\boldsymbol{y}}(t, \boldsymbol{z})\right)$ determined by (2.1-2.7) as:

$$
\frac{\partial \boldsymbol{P}}{\partial t}+\nabla \cdot(\boldsymbol{v} \boldsymbol{P})=\boldsymbol{Q}_{2}
$$


Thus left side of (4.2) describes change of transaction impulses $\boldsymbol{P}(t, \boldsymbol{z})=\left(\boldsymbol{P}_{\boldsymbol{x}}(t, \boldsymbol{z}), \boldsymbol{P}_{\boldsymbol{y}}(t, \boldsymbol{z})\right)(2.3-2.7)$ due to change in time $\partial \boldsymbol{P} / \partial t$ and due to flux $\boldsymbol{v P}$ through surface of unit volume that equals divergence $\nabla \cdot(\boldsymbol{v P})$. Right hand side $\boldsymbol{Q}_{2}$ describes action of other factors on evolution of transaction impulses $\boldsymbol{P}(t, \boldsymbol{z})$. Economic equations $(4.1 ; 4.2)$ present a balance relations between changes of transactions $C L(t, z)$ and their impulses $\boldsymbol{P}(t, \boldsymbol{z})$ in the left side and action of other factors that can induce these changes in the right side.

To describe a particular economic model via equations $(4.1 ; 4.2)$ let's determine direct form of right hand side $Q_{1}$ and $\boldsymbol{Q}_{2}$. Macro transactions $C L(t, \boldsymbol{z})$ and their impulses $\boldsymbol{P}(t, \boldsymbol{z})$ can depend on other transactions and on other economic factors like expectations, for example. In this paper we present the business cycle model in the approximation that takes into account interactions between different transactions only and neglects impact macroeconomic variables or expectations and other economic factors. We shall describe impact of expectations in forthcoming publications. Here we propose that all extensive macro variables are determined by macro transactions or depend on variables that are described by macro transactions.

Equations $(4.1 ; 4.2)$ allow describe evolution of transactions under action of $Q_{1}$ and $\boldsymbol{Q}_{2}$ for two economic approximations. First approximation describes transactions and their mutual extensive variables under given exogenous impact determined by $Q_{1}$ and $\boldsymbol{Q}_{2}$. In other words one studies evolution of transactions under given action of known exogenous factors $Q_{1}$ and $\boldsymbol{Q}_{2}$. The second approximation permits describe self-consistent evolution of transactions under their mutual interaction due to equations $(4.1 ; 4.2)$. Real economic and financial transactions depend on numerous factors and that makes description extremely complex. We propose to start with the simplest case that models mutual interactions between two transactions. For this case left side of $(4.1 ; 4.2)$ describe transaction 1 and factors $Q_{1}$ and $\boldsymbol{Q}_{2}$ are determined by transaction 2 and vice versa. Such approximation gives simple self-consistent model of mutual evolution of two interacting transactions and allows describe the business cycle model related to fluctuations of macro variables determined by these transactions. Below we study self-consistent model that describe mutual interaction between Credits $C L(t, z)$ and Loan-Repayment $L R(t, z)$ transactions. As consequences we describe the business cycle time fluctuations of macro Credits $C(t)$ and macro Loans $L(t)$.

Let's study simplest case and assume that Credits transactions $C L(t, z)$ in the left side of $(4.1 ; 4.2)$ depend on $Q_{1}$ and $\boldsymbol{Q}_{2}$ that determined by Loan-Repayment $L R(t, z)$ transactions. LoanRepayment $L R(t, z)$ transactions describe payout on Credits by Borrowers from point $\boldsymbol{y}$ to Creditors at point $\boldsymbol{x}$. Let's describe evolution of Loan-Repayment $L R(t, z)$ transactions by left side of equations similar to $(4.1 ; 4.2)$ with $Q_{1}$ and $\boldsymbol{Q}_{2}$ determined by Credits transactions $C L(t, z)$. We propose that Credits from $\boldsymbol{x}$ to $\boldsymbol{y}$ and Loan-Repayments from $\boldsymbol{y}$ to $\boldsymbol{x}$ are made at same time $t$ and vice versa. Such assumptions simplify mutual dependence between Credits transactions $C L(t, z)$ and Loan-Repayment $L R(t, z)$ and allow describe the business cycle fluctuations of macro Credits $C(t)$ issued at time $t$.

\section{How macro transactions describe the business cycles}

In (Olkhov, 2017d-e) we proposed that agents perform only local transactions with agents at same point $\boldsymbol{x}$. Such simplifications describe interactions between macro variables at point $\boldsymbol{x}$ by local operators. In this paper we model transactions that can occur between agents at arbitrary points $\boldsymbol{x}$ and $\boldsymbol{y}$. Such transactions describe non-local economic and financial "action-at-a-distance" between e-particles (agents) at points $\boldsymbol{x}$ and $\boldsymbol{y}$ on e-space $R^{n}$. Below we describe the business cycles determined by non-local Credit $C L(t, z)$ and Loan-Repayment $L R(t, z)$ transactions. Let's assume that $C L(t, z)$ at point $z=(\boldsymbol{x}, \boldsymbol{y})$ on e-space $R^{2 n}$ depend on Loan-Repayment $L R(t, z)$ transactions and 
their impulses $\boldsymbol{D}(t, z)$ only and vice versa. Let's assume that $Q_{11}$ for equation (4.1) on transactions $C L(t, z)$ at point $(t, z)$ is proportional to scalar product of vector $z$ and Loan-Repayment impulse $\boldsymbol{D}(t, z)$

$$
Q_{11}=a \mathbf{z} \cdot \boldsymbol{D}(t, \mathbf{z})=a\left(\boldsymbol{x} \cdot \boldsymbol{D}_{x}(t, \mathbf{z})+\boldsymbol{y} \cdot \boldsymbol{D}_{\boldsymbol{y}}(t, \mathbf{z})\right)
$$

Loan-Repayment impulse $\boldsymbol{D}(t, \boldsymbol{z})$ and velocity $\boldsymbol{u}(t, \boldsymbol{z})$ are determined similar to (2.1-2.7). Let's assume that same relations define factor $Q_{12}$ for equation (4.1) on Loan-Repayment $L R(t, z)$ macro transactions:

$$
Q_{12}=b \mathbf{z} \cdot \boldsymbol{P}(t, \mathbf{z})=b\left(\boldsymbol{x} \cdot \boldsymbol{P}_{\boldsymbol{x}}(t, \mathbf{z})+\boldsymbol{y} \cdot \boldsymbol{P}_{\boldsymbol{y}}(t, \mathbf{z})\right)
$$

Here $a$ and $b$-const and equations on transactions $C L(t, z)$ and $L R(t, z)$ take form:

$$
\begin{aligned}
& \frac{\partial C L}{\partial t}+\nabla \cdot(\boldsymbol{v} C L)=Q_{11}=a \mathbf{z} \cdot \boldsymbol{D}(t, \mathbf{z})=a\left(\boldsymbol{x} \cdot \boldsymbol{D}_{\boldsymbol{x}}(t, \mathbf{z})+\boldsymbol{y} \cdot \boldsymbol{D}_{\boldsymbol{y}}(t, \mathbf{z})\right) \\
& \frac{\partial L R}{\partial t}+\nabla \cdot(\boldsymbol{u} L R)=Q_{12}=b \mathbf{z} \cdot \boldsymbol{P}(t, \mathbf{z})=b\left(\boldsymbol{x} \cdot \boldsymbol{P}_{\boldsymbol{x}}(t, \mathbf{z})+\boldsymbol{y} \cdot \boldsymbol{P}_{\boldsymbol{y}}(t, \mathbf{z})\right) \\
& \boldsymbol{P}(t, \mathbf{z})=\boldsymbol{v}(t, \mathbf{z}) C L(t, \mathbf{z}) ; \boldsymbol{D}(t, \mathbf{z})=\boldsymbol{u}(t, \mathbf{z}) L R(t, \mathbf{z})
\end{aligned}
$$

Economic meaning of (5.1-5.3) is as follows. $C L(t, z)$ at point $(t, z)$ grows up if $Q_{11}$ is positive. A position vector $z$ has origin at secure point 0 and points to risky point $z$. Hence for $a>0$ positive value of $\boldsymbol{z} \cdot \boldsymbol{D}(t, \boldsymbol{x})$ models Loan-Repayment flow

$$
\boldsymbol{D}(t, \mathbf{z})=L R(t, \mathbf{z}) \boldsymbol{u}(t, \mathbf{z})
$$

in risky direction $z$ and that can induce growth of Credits $C L(t, z)$ to risky points. As well negative value of $\boldsymbol{z} \cdot \boldsymbol{D}(t, \boldsymbol{z})$ models Loan-Repayment flows from risky to secure domain and that can decrease Credits $C L(t, z)$ as Creditors can prefer more secure Borrowers. This model simplifies Credit modelling as it neglect time gaps between providing Credits from $\boldsymbol{x}$ to $\boldsymbol{y}$ and LoanRepayment received from Borrowers at $\boldsymbol{y}$ to Creditors at $\boldsymbol{x}$ and neglect other factors that can impact on Credits allocation. To determine $\boldsymbol{Q}_{21}$ factor for (4.2) on Credit impulses $\boldsymbol{P}(t, \boldsymbol{z})$ let's assume that $\boldsymbol{Q}_{21}$ is a linear operator and in a matrix form takes form:

$$
\boldsymbol{Q}_{21}=\widehat{\Omega} \boldsymbol{D}(t, \mathbf{z})=\Omega_{i j} D_{j}(t, \mathbf{z})
$$

Let's assume that $\boldsymbol{Q}_{22}$ factor that define equations (4.2) on Loan-Repayment impulses $\boldsymbol{L}(t, \boldsymbol{z})$ is similar linear operator:

$$
\boldsymbol{Q}_{22}=\widehat{\Phi} \boldsymbol{P}(t, \boldsymbol{z})=\Phi_{i j} P_{j}(t, \mathbf{z})
$$

and equations (4.2) for impulses $\boldsymbol{P}(t, \boldsymbol{z})$ and $\boldsymbol{L}(t, \boldsymbol{z})$ take form:

$$
\begin{aligned}
& \frac{\partial \boldsymbol{P}}{\partial t}+\nabla \cdot(\boldsymbol{v} \boldsymbol{P})=\boldsymbol{Q}_{21}=\Omega \boldsymbol{D}(t, \mathbf{z})=\Omega_{i j} D_{j}(t, \mathbf{z})=\Omega_{x i j} D_{x j}(t, \mathbf{z})+\Omega_{y i j} D_{y j}(t, \mathbf{z}) \\
& \frac{\partial \boldsymbol{D}}{\partial t}+\nabla \cdot(\boldsymbol{u} \boldsymbol{D})=\boldsymbol{Q}_{22}=\Phi \boldsymbol{P}(t, \mathbf{z})=\Phi_{i j} P_{j}(t, \mathbf{z})=\Phi_{x i j} P_{x j}(t, \mathbf{z})+\Phi_{y i j} P_{y j}(t, \mathbf{z})
\end{aligned}
$$

Equations (5.4-5.5) describe simple linear mutual dependence between transaction impulses $\boldsymbol{P}(t, \boldsymbol{z})$ and $\boldsymbol{D}(t, z)$. Economic meaning of equations $(5.4 ; 5.5)$ can be explained as follows. Let's mention that integral of each component of impulses $\boldsymbol{P}(t, \boldsymbol{z})$ or its components $P_{x i}(t, z)$ and $P_{y i}(t, \boldsymbol{z})$ along axes $x_{i}$ or $y_{i}$ over $d \boldsymbol{z}$ define total macro impulses $\boldsymbol{P}(t)$ and its components $P_{x i}(t)$ or $P_{y i}(t)$ along risk axis $x_{i}$ or $y_{i}$ and due to (2.7; A.6.3.1; A.6.3.2): 


$$
\begin{array}{r}
P_{x i}(t)=\int d \boldsymbol{z} P_{x i}(t, \mathbf{z})=\int d \boldsymbol{x} d \boldsymbol{y} P_{x i}(t, \boldsymbol{x}, \boldsymbol{y})=C(t) v_{x i}(t) \\
\boldsymbol{P}(t)=\left(\boldsymbol{P}_{x}(t) ; \boldsymbol{P}_{y}(t)\right) ; \boldsymbol{P}_{x}(t)=C(t) \boldsymbol{v}_{x}(t) ; \boldsymbol{P}_{y}(t)=C(t) \boldsymbol{v}_{y}(t)
\end{array}
$$

Similar to total Credits $C(t)$ (3.2) let's define total Repayments $R(t)$ :

$$
R(t)=\int d \boldsymbol{x} d \boldsymbol{y} L R(t, \boldsymbol{x}, \boldsymbol{y})
$$

$R(t)$ - total repayments on Credits in the entire economics. Total impulses $\boldsymbol{P}(t)$ (5.7) have component of Creditors impulses $\boldsymbol{P}_{x}(t)$ along axes $\boldsymbol{x}$ and component $\boldsymbol{P}_{\boldsymbol{y}}(t)$ of Borrowers impulses along axes $\boldsymbol{y}$. Total impulses (5.6) describe motion of macro Credits $C(t)$ on e-space along each risk axes $x_{i}$. Motion of macro Credits $C(t)$ on e-space is reduced by bounds of economic domain (1.1) along each risk axes. Thus motion of macro Credits $C(t)$ in the risky direction should change with motion from risky to secure direction on economic domain (1.1) and thus Credits impulses $\boldsymbol{P}(t)$ should fluctuate. Fluctuations of impulses $\boldsymbol{P}(t)$ describe motion of macro Credits $C(t)$ from secure to risky domain and then from risky to secure. We regard the business cycles of macro variables as oscillations of their impulses $\boldsymbol{P}(t)$. As we show below equations $(5.2 ; 5.3)$ lead to equations (A.6.4-6.8) that describe fluctuations of total Credits impulses $\boldsymbol{P}(t)(5.6 ; 5.7)$.

To describe the Credit cycles we start with system of equations (5.1-5.5) on Credit $C L(t, z)$ and Loan-Repayment $L R(t, z)$ transactions and their impulses $\boldsymbol{P}(t, \boldsymbol{z})$ and $\boldsymbol{D}(t, \boldsymbol{z})$. From these equations we derive the system of ODE (Appendix: A.4; A.8.4-7; A.10.1-10.2) on aggregate variables $C(t)$, $R(t)$ and present elementary solutions (A.11) for the Credit cycle fluctuations under action of a single risk. The simplest case of Credit cycles $C(t)$ under action of a single risk can be derived from (A.11) with $C(j)=$ const $, j=0,1,2,3$ :

$$
C(t)=C(0)+a[C(1) \sin \omega t+C(2) \cos v t+C(3) \exp \gamma t]
$$

Due to $(3.10 ; 6.1)$ macro Credits $M C(t)$ provided in economy during time term $[0, t]$ :

$$
M C(t)=M C(0)+\left[C(0) t+a \frac{C(3)}{\gamma} \exp \gamma t\right]+a\left[\frac{C(2)}{v} \sin v t-\frac{C(1)}{\omega} \cos \omega t\right]
$$

Relations $(6.1 ; 6.2)$ describe the business cycle fluctuations of total Credits $C(t)$. Frequencies of business cycle fluctuations are determined by oscillations of Creditors impulses $P_{x}(t)$ with frequencies $\omega$ and oscillations of Borrowers impulses $P_{y}(t)$ with frequencies $v$ (A.8.4-7). Business cycle fluctuations $(6.1 ; 6.2)$ may happen about exponential growth trend $\exp (\gamma t)(\mathrm{A} .10 .1-2)$ and we take coefficient $\gamma=\max \left(\gamma_{x}, \gamma_{y}\right)$. Thus $\gamma$ describes maximum growth trend induced by (A.8.6-7; A.9.1-2; A.10.1-2). Factors (A.8.8-9) are proportional to product of total Credits $C(t)$ and transactions velocity squared $v^{2}(t)$ and we call them as Credits "energy" because they looks like kinetic energy of a body with mass $C(t)$ and velocity squared $v^{2}(t)$. However meaning of Credits "energy" have nothing common with energy in physics.

Macro Credits $M C(t)$ during time term [0,t] are described by (6.2). If the initial value $C(0)$ is non zero then macro Credits $M C(t)$ has linear and exponential growth trend and oscillations with same frequencies $\omega$ and $v$ about these trends. Solutions (6.1) for Credits transactions $C(t)$ and for Loan-Repayment transactions $R(t)$ present simplest form of Credit cycles under single risk and simple interactions between two macro transactions (Appendix). Action of several risks makes the Credit cycles more complex (A.11). If one neglect growth trend then Credit cycles $C(t)$ under action of $n$ risks can take form (A.11):

$$
C(t)=C(0)+a \sum_{i=1}^{n}\left[C_{x i}(1) \sin \omega_{i} t+C_{x i}(2) \cos \omega_{i} t+C_{y i}(3) \sin v_{i} t+C_{y i}(4) \cos v_{i} t\right]
$$


Relations (6.3) with frequencies $\omega_{i}$ reflect oscillations of Credit impulses $\boldsymbol{P}(t)$ along axes $x_{i}$, and frequencies $v_{i}$ along axes $y_{i}, i=1, . . n$ on $2 n$ dimensional e-space $(\boldsymbol{x}, \boldsymbol{y})$ (Appendix)

\section{Conclusions}

Current business cycle models (Kiyotaki, 2011) are based on general equilibrium theory. "The economy is in general equilibrium when prices have fully adjusted so that supply equals demand in all markets." (Starr, 2011). We assume that economic processes are too diverse, complex and changeable to be described only by general equilibrium theory. Occam's razor (Baker, 2007) principle states that the less initial assumptions are made in the model - the better. Thus it is reasonable develop economic and business cycle theory on base of econometric data only and without ad hoc assumptions of general equilibrium. It is obvious that any economy is an open system and for sure any economic model should depend on numerous exogenous phenomena and factors. Meanwhile it is important to understand and describe internal, endogenous economic properties and relations that govern macroeconomic evolution and development. In this paper we study and model endogenous economic processes that induce and manage macroeconomic business cycles.

We propose that econometrics provides sufficient data for risk assessments of all agents of entire economics and suggest use agent's ratings $\boldsymbol{x}$ as their coordinates. All extensive economic or financial variables are defined as sum of corresponding variables of agents near point $\boldsymbol{x}$. Economic and financial transactions between agents are the only tools for change of agents variables. We aggregate similar transactions between agents at $\boldsymbol{x}$ and $\boldsymbol{y}$ and describe evolution of macro transactions by economic equations (4.1-4.2). Motion of transactions can be treated alike to motion of fluids and is determined by average collective velocity of agents. For example motion of Credit transactions is determined by collective risk velocity of Creditors at $x$ and Borrowers at $\boldsymbol{y}(2.6 ; 2.7)$. Macro impulses and velocities (5.6-5.7) define motion of Creditors $(3.2 ; 3.11)$ along risk axis $\boldsymbol{x}$ and Borrowers along $\boldsymbol{y}$. Collective motions of Creditors and Borrowers occur on economic domain (1.1) that is bounded by minimum and maximum risk grades. Hence macro motion (5.6-5.7) of Creditors and Borrowers from safer to risky direction should change by opposite motion from risky to safer area. We show that oscillations of Creditors and Borrowers motion on economic domain from safer to risky direction and back induce macroeconomic Credit cycles. The same relations govern the business cycles of Investment and Consumption, Demand and Supply and etc. Motions of the same economic agents generate the business cycles of different macroeconomic variables and that explain coherence and interactions between cycles of different macroeconomic variables. Economic evolution under action of several risks and interactions between numerous economic and financial transactions makes description of the business cycles on multi-dimensional economic space rather complex problem. This paper describes the business cycles in the approximation that takes into account interactions between different transactions only and neglects action of expectations. Even such simplification uncovers rich and complex relations between transactions that govern the business cycles. We'll describe impact of expectations on the business cycles in forthcoming paper.

Econometric assessments of risk ratings of economic agents use corporate financial accounting and reporting. Thus unification of accounting methodologies becomes important as for macroeconomic forecasting as for corporate reporting itself. Unified corporate reporting establishes ground for correct risk assessments and macroeconomic forecasting on economic space. It helps define corporate risk ratings and risk motion and is important for corporate management and shareholders as tool for assessment of corporate risk trajectory. Assessments of 
Credits, Investment, Demand and etc. cycles and modelling evolution of corporate risk state can improve management, performance and sustainability of economic development.

We propose that no principal obstacles prevent development of econometrics in a way sufficient risk assessment of economic agents and modelling business cycles. We hope that our theory can help financial authorities, Central Banks, business and academic researchers improve forecasting and management of the business cycles. 


\section{Appendix}

\section{Economic Transactions and The Business Cycle Equations}

Let's study transactions between agents on $n$-dimensional e-space $R^{n}$. We use standard notations: bold letters like $\boldsymbol{P}, \boldsymbol{v}, \boldsymbol{x}, \boldsymbol{y}, \boldsymbol{z}$ define vectors and roman $C, C L, X, \ldots$ - scalars. Vector $\boldsymbol{z}=(\boldsymbol{x}, \boldsymbol{y})$ is defined on $2 n$-dimensional e-space $R^{2 n}$. Scalar product:

$$
\boldsymbol{z} \cdot \boldsymbol{P}=\boldsymbol{x} \cdot \boldsymbol{P}_{\boldsymbol{x}}+\boldsymbol{y} \cdot \boldsymbol{P}_{\boldsymbol{y}}=\sum_{i=1, \ldots n} x_{i} P_{x i}+\sum_{i=1, \ldots n} y_{i} P_{y i}
$$

To derive a system of ODE on Credits $C(t)$ and Loan-Repayments $L R(t)$ let's start with equations (5.1). For economics under action of $n$ risks Credits transactions $C L(t, z)$ are determined on $2 n$ dimensional economic domain $(1.1), z=(x, y)$ :

$$
0 \leq x_{i} \leq X_{i} ; 0 \leq y_{i} \leq X_{i} i=1, \ldots n
$$

Let's remind that similar to (1.1) values of $X_{i}$ can be set as $X_{i}=1$. To derive equations on $C(t)$ (3.2) let's take integral by $d z=d x d y$ of equation (5.1):

$$
\frac{d}{d t} C(t)=\frac{d}{d t} \int d \mathbf{z} C L(t, \mathbf{z})=-\int d \mathbf{z} \nabla \cdot(\boldsymbol{v}(t, \mathbf{z}) C L(t, \mathbf{z}))+a \int d \mathbf{z} \mathbf{z} \cdot \boldsymbol{D}(t, \mathbf{z})(\text { A.2.1) }
$$

First integral in the right side (A.2.1) equals integral of divergence over $2 n$ dimensional e-space and due to divergence theorem (Strauss 2008, p.179) equals integral of flux $v C L$ through surface. Thus first integral in the right side (A.2.1) equals zero as no economic or financial fluxes exist far from boundaries of economic domain (A.1).

and we define $P z(t)$ and $D z(t)$ as:

$$
\int d \mathbf{z} \nabla \cdot(\boldsymbol{v}(t, \mathbf{z}) C L(t, \mathbf{z}))=0
$$

$$
\begin{aligned}
P z(t) & =\int d \boldsymbol{z} \boldsymbol{P}(t, \mathbf{z}) \cdot \mathbf{z}=\int d \boldsymbol{x} d \boldsymbol{y} \sum_{i=1}^{n} x_{i} P_{x i}(t, \boldsymbol{x}, \boldsymbol{y})+\int d \boldsymbol{x} d \boldsymbol{y} \sum_{i=1}^{n} y_{i} P_{y i}(t, \boldsymbol{x}, \boldsymbol{y}) \\
D z(t) & =\int d \mathbf{z} \boldsymbol{D}(t, \mathbf{z}) \cdot \mathbf{z}=\int d \boldsymbol{x} d \boldsymbol{y} \sum_{i=1}^{n} x_{i} D_{x i}(t, \boldsymbol{x}, \boldsymbol{y})+\int d \boldsymbol{x} d \boldsymbol{y} \sum_{i=1}^{n} y_{i} D_{y i}(t, \boldsymbol{x}, \boldsymbol{y})
\end{aligned}
$$

Due to $(3.2 ; 5.1-5.3 ; 5.8 ;$ A.2.1-A.3.2) equations on $C(t)$ and $R(t)$ take form:

$$
\frac{d}{d t} C(t)=a D z(t) \quad ; \quad \frac{d}{d t} R(t)=b P z(t)
$$

To derive equations on $P z(t)$ and $D z(t)$ let's use equations on impulses $\boldsymbol{P}(t), \boldsymbol{D}(t)$. Let's start with $(5.4 ; 5.5)$. To simplify derivation of equations let's take matrix in equations $(5.4 ; 5.5)$ in simplest diagonal form $(i, j=1, . . n)$ :

$$
\begin{aligned}
& \Phi_{i j}=\left(\Phi_{x i j} ; \Phi_{y i j}\right) ; \Phi_{i j} P_{j}=\left(\Phi_{x i j} P_{x j} ; \Phi_{y i j} P_{j y}\right) \\
& \Omega_{i j}=\left(\Omega_{x i j} ; \Omega_{y i j}\right) ; \Omega_{i j} D_{j}=\left(\Omega_{x i j} D_{x j} ; \Omega_{y i j} D_{y y}\right) \\
& \Phi_{x i j}=d_{x i} \delta_{i j} ; \quad \Phi_{y i j}=d_{y i} \delta_{i j} \\
& \Omega_{x i j}=c_{x i} \delta_{i j} ; \Omega_{y i j} c_{y i} \delta_{i j} \\
& \Phi_{x i j} P_{j x}(t, \mathbf{z})=d_{x i} P_{x i}(t, \mathbf{z}) ; \Phi_{y i j} P_{j y}(t, \mathbf{z})=d_{y i} P_{y i}(t, \mathbf{z}) \\
& \quad \Omega_{x i j} D_{x j}(t, \mathbf{z})=c_{x i} D_{x i}(t, \mathbf{z}) ; \Omega_{y i j} D_{y j}(t, \mathbf{z})=c_{y i} D_{y i}(t, \mathbf{z})
\end{aligned}
$$

Thus equations $(5.4 ; 5.5)$ take form $(i=1, . . n)$ : 


$$
\begin{aligned}
& \frac{\partial P_{x i}}{\partial t}+\nabla \cdot\left(\boldsymbol{v} P_{x i}\right)=c_{x i} D_{x i}(t, \mathbf{z}) ; \frac{\partial P_{y i}}{\partial t}+\nabla \cdot\left(\boldsymbol{v} P_{y i}\right)=c_{y i} D_{y i}(t, \mathbf{z}) \\
& \frac{\partial D_{x i}}{\partial t}+\nabla \cdot\left(\boldsymbol{u} D_{x i}\right)=d_{x i} P_{x i}(t, \boldsymbol{z}) ; \frac{\partial D_{i y}}{\partial t}+\nabla \cdot\left(\boldsymbol{u} D_{y i}\right)=d_{y i} P_{y i}(t, \mathbf{z})
\end{aligned}
$$

To derive equations on aggregate impulses $\boldsymbol{P}(t)$ and $\boldsymbol{D}(t)(5.6 ; 5.7)$ and their components $P_{x i} P_{y i}$, $D_{x i}, D_{y i}$ let's take integral by $d \boldsymbol{z}=d \boldsymbol{x} d \boldsymbol{y}$ of equation (A.6.1):

$$
\frac{d}{d t} P_{x i}(t)=\frac{d}{d t} \int d \mathbf{z} P_{x i}(t, \mathbf{z})=-\int d \mathbf{z} \nabla \cdot\left(\boldsymbol{v} P_{x i}\right)+c_{x i} \int d \mathbf{z} D_{x i}(t, \mathbf{z})
$$

Similar relations obey for impulses $D_{x i}, D_{y i}$ :

$$
\begin{aligned}
P_{x i}(t) & =\int d \mathbf{z} P_{x i}(t, \mathbf{z})=C(t) v_{x i}(t) ; P_{y i}(t)=\int d \mathbf{z} P_{y i}(t, \mathbf{z})=C(t) v_{y i}(t) \\
D_{x i}(t) & =\int d \mathbf{z} D_{x i}(t, \mathbf{z})=R(t) u_{x i}(t) ; D_{y i}(t)=\int d \mathbf{z} D_{y i}(t, \mathbf{z})=R(t) u_{y i}(t)
\end{aligned}
$$

Due to same reasons as (A.2.1) first integral in the right side (A.6.3) equals zero and equations (A.6.1; A.6.2) takes form $(i=1, . . n)$ :

$$
\begin{aligned}
& \frac{d}{d t} P_{x i}(t)=c_{x i} D_{x i}(t) ; \frac{d}{d t} D_{x i}(t)=d_{x i} P_{x i}(t) \\
& \frac{d}{d t} P_{y i}(t)=c_{y i} D_{y i}(t) ; \frac{d}{d t} D_{y i}(t)=d_{y i} P_{y i}(t)
\end{aligned}
$$

Due to (A.1) impulses $\boldsymbol{P}(t)=\left(P_{x i}(t), P_{y i}(t)\right), \boldsymbol{D}(t)=\left(D_{x i}(t), D_{y i}(t)\right)$ along each risk axes can't keep positive or negative as in such a case Creditors and Borrowers will reach max or min borders (A.1). Thus impulses along each axes must fluctuate and equations (A.6.6-6.8) describe simplest harmonique oscillations of impulses $\boldsymbol{P}(t)$ and $\boldsymbol{D}(t)$ with frequencies $\omega_{i}, v_{i}$ :

$$
\begin{aligned}
& \omega_{i}^{2}=-c_{x i} d_{x i}>0 ; v_{i}^{2}=-c_{y i} d_{y i}>0 ; i=1, . . n \\
& {\left[\frac{d^{2}}{d t^{2}}+\omega_{i}^{2}\right] P_{x i}(t)=0 ;\left[\frac{d^{2}}{d t^{2}}+\omega_{i}^{2}\right] D_{x i}(t)=0} \\
& {\left[\frac{d^{2}}{d t^{2}}+v_{i}^{2}\right] P_{y i}(t)=0 ;\left[\frac{d^{2}}{d t^{2}}+v_{i}^{2}\right] D_{y i}(t)=0}
\end{aligned}
$$

Frequencies $\omega_{i}, i=1, . . n$ describe fluctuations of Creditors along coordinates $\boldsymbol{x}=\left(x_{1}, . . x_{n}\right)$. Frequencies $v_{i}, i=1, . . n$ describe fluctuations of Borrowers along coordinates $\boldsymbol{y}=\left(y_{1}, . . y_{n}\right)$. Solutions of (A.6.7-8) have form:

$$
\begin{array}{r}
P_{x i}(t)=P_{x i}(1) \sin \omega_{i} t+P_{x i}(2) \cos \omega_{i} t ; P_{y i}(t)=P_{y i}(1) \sin v_{i} t+P_{y i}(2) \cos v_{i} t \quad \text { (A.6.9) } \\
D_{x i}(t)=D_{x i}(1) \sin \omega_{i} t+D_{x i}(2) \cos \omega_{i} t ; D_{y i}(t)=D_{y i}(1) \sin v_{i} t+D_{y i}(2) \cos v_{i} t \quad \text { (A.6.10) }
\end{array}
$$

Thus motions of Creditors and Borrowers on e-space induce oscillations (A.6.9-10) of macro transactions impulses with different frequencies $\omega_{i}$ and $v_{i}$ along risk axes $x_{i}$ or $y_{i}$. To derive equations on $P z(t)$ and $D z(t)$ determined by (A.3.1;A.3.2) let's define their components $P z_{x i}(t) ; P z_{y i}(t) ; D z_{x i}(t) ; D z_{y i}(t)$ as:

$$
\begin{aligned}
& P z_{x i}(t)=\int d \boldsymbol{x} d \boldsymbol{y} x_{i} P_{x i}(t, \boldsymbol{x}, \boldsymbol{y}) ; P z_{y i}(t)=\int d \boldsymbol{x} d \boldsymbol{y} y_{i} P_{y i}(t, \boldsymbol{x}, \boldsymbol{y}) \\
& D z_{x i}(t)=\int d \boldsymbol{x} d \boldsymbol{y} x_{i} D_{x i}(t, \boldsymbol{x}, \boldsymbol{y}) ; D z_{y i}(t)=\int d \boldsymbol{x} d \boldsymbol{y} y_{i} D_{y i}(t, \boldsymbol{x}, \boldsymbol{y})
\end{aligned}
$$

Relations (A.3.1;A.3.2) can be presented as:

$$
P z(t)=\sum_{i=1}^{n} P z_{x i}(t)+\sum_{i=1}^{n} P z_{y i}(t)
$$




$$
D z(t)=\sum_{i=1}^{n} D z_{x i}(t)+\sum_{i=1}^{n} D z_{y i}(t)
$$

To define equations on $P z_{x i}(t), P z_{y i}(t), D z_{x i}(t), D z_{y i}(t)$ let's use equations (A.6.1 ; A.6.2). Let's multiply equations (A.6.1) by $x_{i}$ and take integral by $d x d y$

$$
\begin{gathered}
\frac{d}{d t} P z_{x i}(t)=\frac{d}{d t} \int d \boldsymbol{x} d \boldsymbol{y} x_{i} P_{x i}(t, \boldsymbol{x}, \boldsymbol{y})=-\int d \boldsymbol{x} d \boldsymbol{y} x_{i} \nabla \cdot\left(\boldsymbol{v} P_{x i}\right)+c_{x i} \int d \boldsymbol{x} d \boldsymbol{y} x_{i} D_{x i}(t, \mathbf{z}) \\
\int d \boldsymbol{x} d \boldsymbol{y} x_{i} \nabla \cdot\left(\boldsymbol{v} P_{x i}\right)=\int d x_{k \neq i} d \boldsymbol{y} \int d x_{i} x_{i} \frac{\partial}{\partial x_{i}}\left(v_{x i} P_{x i}\right)+\int d x_{i} x_{i} \int d x_{k \neq i} d \boldsymbol{y} \frac{\partial}{\partial x_{k \neq i}}\left(v_{x k \neq i} P_{x i}\right)
\end{gathered}
$$

Second integral equals zero due to same reasons as (A.2.1). Let's take first integral by parts:

$$
\int d x_{i} x_{i} \frac{\partial}{\partial x_{i}}\left(v_{x i} P_{x i}\right)=\int d x_{i} \frac{\partial}{\partial x_{i}}\left(x_{i} v_{x i} P_{x i}\right)-\int d x_{i} v_{x i} P_{x i}
$$

First integral in the right side equals zero and we obtain:

$$
\int d \boldsymbol{x} d \boldsymbol{y} x_{i} \nabla \cdot\left(\boldsymbol{v} P_{x i}\right)=-\int d \boldsymbol{x} d \boldsymbol{y} v_{i} P_{x i}=-\int d \boldsymbol{x} d \boldsymbol{y} v_{i}^{2}(t, \boldsymbol{x}, \boldsymbol{y}) C L(t, \boldsymbol{x}, \boldsymbol{y})
$$

Let's denote as

$$
\begin{aligned}
& E C x_{i}(t)=\int d \boldsymbol{x} d \boldsymbol{y} v_{x i}^{2}(t, \boldsymbol{x}, \boldsymbol{y}) C L(t, \boldsymbol{x}, \boldsymbol{y}) ; E C y_{i}(t)=\int d \boldsymbol{x} d \boldsymbol{y} v_{y i}^{2}(t, \boldsymbol{x}, \boldsymbol{y}) C L(t, \boldsymbol{x}, \boldsymbol{y})( \\
& E R x_{i}(t)=\int d \boldsymbol{x} d \boldsymbol{y} u_{x i}^{2}(t, \boldsymbol{x}, \boldsymbol{y}) L R(t, \boldsymbol{x}, \boldsymbol{y}) ; E R y_{i}(t)=\int d \boldsymbol{x} d \boldsymbol{y} u_{y i}^{2}(t, \boldsymbol{x}, \boldsymbol{y}) L R(t, \boldsymbol{x}, \boldsymbol{y})
\end{aligned}
$$

Thus equations on $\mathrm{Pz}_{\mathrm{xi}}(\mathrm{t}), \mathrm{Pz}_{\mathrm{yi}}(\mathrm{t}), \mathrm{D} \mathrm{z}_{\mathrm{xi}}(\mathrm{t}), \mathrm{Dz} \mathrm{y}_{\mathrm{yi}}(\mathrm{t})$ take form:

$$
\begin{aligned}
& \frac{d}{d t} P z_{x i}(t)=E C x_{i}(t)+c_{x i} D z_{x i}(t) ; \frac{d}{d t} D z_{x i}(t)=E R x_{i}(t)+d_{x i} P z_{x i}(t) \\
& \frac{d}{d t} P z_{y i}(t)=E C y_{i}(t)+c_{y i} D z_{y i}(t) ; \frac{d}{d t} D z_{y i}(t)=E R y_{i}(t)+d_{y i} P z_{y i}(t)
\end{aligned}
$$

Due to relations (A.6.6) equations on $P z_{x i}(t), P z_{y i}(t), D z_{x i}(t), D z_{y i}(t)$ can be presented as:

$$
\begin{aligned}
& {\left[\frac{d^{2}}{d t^{2}}+\omega_{i}^{2}\right] P z_{x i}(t)=\frac{d}{d t} E C x_{i}(t)+c_{x i} E R x_{i}(t)} \\
& {\left[\frac{d^{2}}{d t^{2}}+\omega_{i}^{2}\right] D z_{x i}(t)=\frac{d}{d t} E R x_{i}(t)+d_{x i} E C x_{i}(t)} \\
& {\left[\frac{d^{2}}{d t^{2}}+v_{i}^{2}\right] P z_{y i}(t)=\frac{d}{d t} E C y_{i}(t)+c_{y i} E R y_{i}(t)} \\
& {\left[\frac{d^{2}}{d t^{2}}+v_{i}^{2}\right] D z_{y i}(t)=\frac{d}{d t} E R y_{i}(t)+d_{y i} E C y_{i}(t)}
\end{aligned}
$$

Equations (A.8.4-8.7) describe fluctuations of $P z_{x i}(t), P z_{y i}(t), D z_{x i}(t), D z_{y i}(t)$ with frequencies $\omega_{i}, v_{i}$ under action of right-hand side factors $E C x_{i}, E C y_{i} E R x_{i}, E R y_{i}$ (see below (A.9.1-10.2)). To derive ODE (A.4; A.8.4-7) in a closed form let's derive equations on $E C x_{i}(t), E C y_{i}(t), E R x_{i}(t), E R y_{i}(t)$. Let's outline that relations (A.8.2-8.3; A.8.8-8.9) are proportional to product of Credits $C(t)$ and velocity squared $v^{2}(t)$.

$$
\begin{aligned}
& E C(t)=C(t) v^{2}(t)=\int d \boldsymbol{x} d \boldsymbol{y} v^{2}(t, \boldsymbol{x}, \boldsymbol{y}) C L(t, \boldsymbol{x}, \boldsymbol{y})=\sum_{i=1}^{n} E C x_{i}(t)+E C y_{i}(t) \\
& E R(t)=R(t) u^{2}(t)=\int d \boldsymbol{x} d \boldsymbol{y} u^{2}(t, \boldsymbol{x}, \boldsymbol{y}) L R(t, \boldsymbol{x}, \boldsymbol{y})=\sum_{i=1}^{n} E R x_{i}(t)+E R y_{i}(t)
\end{aligned}
$$


Factors $E C x_{i}(t)$ and $E C y_{i}(t)$ (A.8.2-8.3) are components of $E C(t)$ along each axes $x_{i}$ and $y_{i}$. Factors $E C(t)=C(t) v^{2}(t)(\mathrm{A} .8 .8-8.9)$ are alike to kinetic "energy" of particle with mass $C(t)$ and velocity squared $v^{2}(t)$ but these similarities have no further analogies. Equations on $E C x_{i}(t, z)$ and $E C y_{i}(t, z)$ take form similar to (4.1):

$$
\begin{aligned}
& \frac{\partial}{\partial t} E C x_{i}(t, \mathbf{z})+\nabla \cdot\left(\boldsymbol{v} E C x_{i}\right)=Q E C x_{i} ; \frac{\partial}{\partial t} E C y_{i}(t, \mathbf{z})+\nabla \cdot\left(\boldsymbol{v} E C y_{i}\right)=Q E C y_{i} \\
& \frac{\partial}{\partial t} E R x_{i}(t, \mathbf{z})+\nabla \cdot\left(\boldsymbol{u} E R x_{i}\right)=Q E R x_{i} ; \quad \frac{\partial}{\partial t} E R y_{i}(t, \mathbf{z})+\nabla \cdot\left(\boldsymbol{u} E R y_{i}\right)=Q E R y_{i}
\end{aligned}
$$

Let's propose that factors $Q E C x_{i}$ take form of diagonal matrix as:

$$
\begin{gathered}
Q E C x_{i}=\mathrm{M}_{x i j} E R x_{j}=\mu_{x i} E R x_{i} ; \quad \mathrm{M}_{x i j}=\mu_{x i} \delta_{i j} \\
Q E C y_{i}=\mathrm{M}_{y i j} E R y_{j}=\mu_{y i} E R y_{i} ; \quad \mathrm{M}_{y i j}=\mu_{y i} \delta_{i j} \mu_{y i} \\
Q E R x_{i}=\mathrm{N}_{x i j} E C x_{j}=\eta_{x i} E C x_{i} ; \mathrm{N}_{x i j}=\eta_{x i} \delta_{i j} \\
Q E R y_{i}=\mathrm{N}_{y i j} E C y_{j}=\eta_{y i} E C y_{i} ; \mathrm{N}_{y i j}=\eta_{y i} \delta_{i j} \\
\gamma_{x i}^{2}=\mu_{x i} \eta_{x i}>0 ; \gamma_{y i}^{2}=\mu_{y i} \eta_{y i}>0
\end{gathered}
$$

Similar to derivation of equations on impulses $P_{x i}(t), P_{y i}(t), D_{x i}(t), D_{y i}(t)$ (A.6.4-A.6.8) equations (A.9.1-7) give equations on $E C x_{i}(t), E C y_{i}(t), E R x_{i}(t), E R y_{i}(t)$ :

$$
\begin{aligned}
& {\left[\frac{d^{2}}{d t^{2}}-\gamma_{x i}^{2}\right] E C_{x i}(t)=0 ;\left[\frac{d^{2}}{d t^{2}}-\gamma_{x i}^{2}\right] E R_{x i}(t)=0} \\
& {\left[\frac{d^{2}}{d t^{2}}-\gamma_{y i}^{2}\right] E C_{y i}(t)=0 ;\left[\frac{d^{2}}{d t^{2}}-\gamma_{y i}^{2}\right] E R_{y i}(t)=0}
\end{aligned}
$$

Economic meaning of (A.9.1-A.9.7) is as follows: "energies" $E C x_{i}(t), E C y_{i}(t), E R x_{i}(t), E R y_{i}(t)$ grow up or decay in time by exponent $\exp \left(\gamma_{x i} t\right)$ and $\exp \left(\gamma_{y i} t\right)$ that can be different for each risk axis $i=1, . . n$. Here $\gamma_{x i}$ define exponential growth or decay in time of $E C x_{i}(t)$ induced by motion of Creditors along axes $x_{i}$ and $\gamma_{y i}$ and same time describe exponential growth or decrease in time of $E C y_{i}(t)$ induced by motion of Borrowers along axes $y_{i}$. The same valid for $E R x_{i}(t), E R y_{i}(t)$ respectively. Let's underline that due to (A.8.8) velocity squared $v^{2}(t)$ is not equals to square of velocity $\boldsymbol{v}(t)=\left(\boldsymbol{v}_{x}(t), \boldsymbol{v}_{y}(t)\right)$ determined by (5.6-5.8). Thus (A.8.4-8.7) and (A.10.1-10.2) are consistent equations. Equations (A.4; A.8.4-7; A.10.1-2) describe a closed system of ODE that models time evolution of aggregate variables $C(t), R(t), P z_{x i}(t), P z_{y i}(t), D z_{x i}(t), D z_{y i}(t), E C x_{i}(t), E C y_{i}(t)$, $E R x_{i}(t), E R y_{i}(t)$ and solutions (A.4; A.8.4-7; A.10.1-2) have form:

$$
\begin{gathered}
E C_{x i}(t)=E C_{x i}(1) \exp \gamma_{x i} t+E C_{x i}(2) \exp -\gamma_{x i} t ; E C_{y i}(t)=E C_{y i}(1) \exp \gamma_{y i} t+E C_{y i}(2) \exp -\gamma_{y i} t \\
E R_{x i}(t)=E R_{x i}(1) \exp \gamma_{x i} t+E R_{x i}(2) \exp -\gamma_{x i} t ; E R_{y i}(t)=E R_{y i}(1) \exp \gamma_{y i} t+E R_{y i}(2) \exp -\gamma_{y i} t \\
P z_{x i}(t)=P z_{x i}(1) \sin \omega_{i} t+P z_{x i}(2) \cos \omega_{i} t+P z_{x i}(3) \exp \gamma_{x i} t+P z_{x i}(4) \exp -\gamma_{x i} t \\
P z_{y i}(t)=P z_{y i}(1) \sin v_{i} t+P z_{y i}(2) \cos v_{i} t+P z_{y i}(3) \exp \gamma_{y i} t+P z_{y i}(4) \exp -\gamma_{y i} t \\
D z_{x i}(t)=D z_{x i}(1) \sin \omega_{i} t+D z_{x i}(2) \cos \omega_{i} t+D z_{x i}(3) \exp \gamma_{x i} t+D z_{x i}(4) \exp -\gamma_{x i} t \\
D z_{y i}(t)=D z_{y i}(1) \sin v_{i} t+D z_{y i}(2) \cos v_{i} t+D z_{y i}(3) \exp \gamma_{y i} t+D z_{y i}(4) \exp -\gamma_{y i} t
\end{gathered}
$$

Total Credits $C(t)$ as solution of (A.4; A.7.4) have form:

$$
\begin{aligned}
C(t)=C(0) & +a \sum_{i=1}^{n}\left[C_{x i}(1) \sin \omega_{i} t+C_{x i}(2) \cos \omega_{i} t+C_{y i}(3) \sin v_{i} t+C_{y i}(4) \cos v_{i} t\right] \\
& +a \sum_{i=1}^{n}\left[C_{x i}(5) \exp \gamma_{x i} t+C_{x i}(6) \exp -\gamma_{x i} t+C_{y i}(7) \exp \gamma_{y i} t+C_{y i}(8) \exp -\gamma_{y i} t\right]
\end{aligned}
$$

Simple but long relations define constants $C_{x i}(j), C_{y i}(j), j=0, . .8$ that are determined by initial values and equations (A.4; A.8.4-7; A.10.1-2) and we omit them here. Solutions (A.11) allow obtain simple relations on macro Credits $M C(t)(3.10 ; 3.11)$. 


\section{References}

Alvarez. F. \& Jermann, U.J. (1999). Efficiency, Equilibrium, and Asset Pricing with Risk of Default. Econometrica, $68,775-797$.

Arrow, K.J. \& Debreu, G. (1954). Existence of an Equilibrium for a Competitive Economy. Econometrica, 22, 265290.

Arrow, K.J. (1974). General Economic Equilibrium: Purpose, Analytic Techniques, Collective Choice. Am. Economic Rev., 64, (3), 253-27.

Baker, A. (2007). Occam's Razor in science: a case study from biogeography. Biology and Philosophy, 22, $193-215$.

Bilbiie, F.O., Ghironi, F., \& Melitz, M.J. (2012). Endogenous Entry, Product Variety, and Business Cycles. Journal of Political Economy, 120, (2), 304-345.

BIS, (2014). Foundations of the standardized approach for measuring counterparty credit risk exposures. Bank for International Settlements, WP 26

Bollerslev, T. \& Zhang B.Y.B. (2003). Measuring and modelling systematic risk in factor pricing models using highfrequency data. Journal of Empirical Finance, 10, 533-558.

Bordalo, P., Gennaioli, N., \& Shleifer, A. (2016). Diagnostic Expectations and Credit Cycles. NBER, WP 22266.

Brunnermeier, M.K., \& Parker, J.A. (2005). Optimal Expectations. American Economic Review, 95 (4), $1092-$ 1118.

Campbell, J.Y. (2016). Restoring Rational Choice: The Challenge of Consumer Financial Regulation. American Economic Review, 106, (5), 1-30.

Cardenete, M.A., Guerra, A.I., \& Sancho, F. (2012). Applied General Equilibrium. An Introduction. Springer-Verlag Berlin

Chane-Kon, L., Neugebauer, M., Pak, A., Trebach, K., \& Tsang, E. (2010). Structured Finance. Global Rating Criteria for Structured Finance CDOs, Fitch Ratings, 1-27

Christiano, L., Motto, R., \& Rostagno, M. (2013). Risk Shocks. NBER WP18682. Cambridge, MA.

Del Negro, M. et.al., (2013). The FRB NY DSGE Model. FRB of NY, Staff Rep. 647.

Diebold, F.X., \& Rudebusch, G.D. (1999). Business Cycles Durations, Dynamics, and Forecasting. Princeton Univ.Press.

Diebold, F.X. (Ed), (2012). Financial Risk Measurement and Management. International Library of Critical Writings in Economics. Edward Elgar Publishing Ltd.

Diebold, F.X. \& Yilmaz, K. (2013). Measuring the Dynamics of Global Business Cycle Connectedness. PIER WP 13-070, Penn Inst. for Economic Research, Univ. Pennsylvania.

Dotsey, M. \& King, R.G. (1988). Rational Expectations Business Cycle Models: A Survey. FRB Richmond, March/April, 3-15

Engle, R. (2017). Systemic Risk With Endogenous Cycles. Conf. "Banks, Systemic Risk, Measurement and Mitigation. Sapienza Univ., Rome.

Farmer, R.E.A., \& Woodford, M. (1997). Self-Fulfilling Prophecies And The Business Cycle, Macroeconomic Dynamics, 1, 740-769.

Fox, D.R., et.al, (2014). Concepts and Methods of the U.S. National Income and Product Accounts. BEA US DoC, 1-373.

Gintis, H. (2007). The Dynamics Of General Equilibrium. The Economic Journal, 117, 1280-1309.

Grandmont, J.M. (1985). On Endogenous Competitive Business Cycles. Econometrica. 53, (5), 995-1045

Greenwood, R., \& Shleifer, A. (2014). Expectations of Returns and Expected Returns. The Review of Financial Studies, 27 (3), 714-746

Grossman, H.I. (1980). Rational Expectations, Business Cycles, and Government Behavior. in "Rational Expectations and Economic Policy" Ed. Fischer, S. NBER, Chicago.

Growiec, J., McAdam, P., \& Mućk, J. (2015). Endogenous labor share cycles: theory and evidence. European Central Bank, WP 1765.

Gupton, G.M., Finger, C.C., \& Bhatia, M. (1997). CreditMetrics ${ }^{\text {TM}}-$ Technical Document. J.P. Morgan \& Co. Incorporated. NY.

Hayek, F.A. von. (1933). Monetary Theory and the Trade Cycle. London, Jonathan Cape.

Huang, X., \& Zhou, H. (2009). A Framework for Assessing the Systemic Risk of Major Financial Institutions, Finance\&Economics Discussion Series, FRB, W., D.C.

Jaimovich, N., \& Rebelo, S. (2007). Behavioral Theories Of The Business Cycle. Journal of the European Economic Association, 5, (2-3), 361-368

Jorda, O., Schularick, M., \& Taylor, A.M. (2016). Macrofinancial History and the New $\quad$ Business Cycle Facts. FRB San Francisco, WP 2016-23

Kiyotaki, N. (2011). A Perspective on Modern Business Cycle Theory. Economic Quarterly, 97, (3), $195-208$.

Kraemer, N., \& Vazza, D. (2012). 2011 Annual U.S. Corporate Default Study And Rating Transitions, S\&P: 1-96 
Kydland, F., \& Prescott, E.C. (1980). A Competitive Theory of Fluctuations and the Feasibility and Desirability of Stabilization Policy, 169 - 198 in Ed. Fisher, S., Rational Expectations and Economic Policy, NBER, Univ. Chicago Press

Kydland, F.E. \& Prescott, E.C. (1982). Time to Build and Aggregate Fluctuations. Econometrica, 50, (6), 1345-1370.

Kydland, F.E. \& Prescott, E.C. (1991). The Econometrics of the General Equilibrium Approach to Business Cycles. Scand. J. of Economics, 93, (2), 161-178.

Landau, L.D. \& Lifshitz, E.M. (1981). Physical kinetics. NY: Pergamon Press Ltd.

Landau, L.D. \& Lifshitz, E.M. (1987). Fluid Mechanics. NY: Pergamon Press Ltd.

Leontief, W. (1973). Structure Of The World Economy. Outline of a Simple Input-Output Formulation. Nobel Memorial Lecture, Harvard University, Massachusetts, USA

Lucas, R.E. (1972). Expectations and the Neutrality of Money. Jour. of Economic Theory, 4, 103-124.

Lucas, R.E. (1975). An Equilibrium Model of Business Cycle. Jour. Political Economy, 83, 1113-1144.

Lucas, R.E. (1980). Methods and Problems in Business Cycle Theory. Jour.of Money, $\quad$ Credit and Banking, 12, (4), Part 2: Rational Expectations, 696-715.

Lucas, R.E. (1995). Understanding Business Cycles, in Estrin, S and A. Marin (ed.), $\quad$ Essential Readings in Economics, 306-327. Macmillan

Manski, C.F. (2017). Survey Measurement Of Probabilistic Macroeconomic Expectations: Progress and Promise. NBER Macro Annual Conference, 1-76.

Mendoza, E.G. \& Yue, V.Z. (2012). A General Equilibrium model Of Sovereign Default And Business Cycles. Quart. Jour. Economics, 127, 889-946.

Metz, A. \& Cantor, R. (2007). Introducing Moody's Credit Transition Model. Moody's Investor Service, 1-26.

Mitchell, W.C. (1927). Business Cycles: The Problem and Its Setting. NBER, 519.

Morgenstern, O. (1959). International Financial Transactions and Business Cycles. NBER, Princeton University Press, 591.

Mullineux, A.D. \& Dickinson, D.G. (1992). Equilibrium Business Cycles: Theory and $\quad$ Evidence. Journal of Economic Surveys, 6, (4), 321-58.

Muth, J.F. (1961). Rational Expectations and the Theory of Price Movements. Econometrica, 29, (3), 315-335.

Nicolò, G.D. \& Lucchetta, M. (2011). Systemic Risks And The Macroeconomy, WP 16998, NBER, Cambridge, MA

Ohanian, L.E., Prescott, E.C., \& Stokey, N.L. (2009). Introduction to dynamic general equilibrium. Journal of Economic Theory, 144, 2235-2246.

Olkhov, V. (2016a). On Economic space Notion. International Review of Financial Analysis, 47, 372-381.

Olkhov, V. (2016b). Finance, Risk and Economic space. ACRN Oxford J. of Finance and Risk Perspectives, 5, 209221.

Olkhov, V. (2017a). Quantitative Wave Model of Macro-Finance. International Review of Financial Analysis, 50, 143150.

Olkhov, V. (2017b). Quantitative Description of Financial Transactions and Risks. ACRN Oxford Journal of Finance and Risk Perspectives, 6, (2), 41-54.

Olkhov, V. (2017c). Credit-Loans Non-Local Transactions and Surface-Like Waves. https://ssrn.com/abstract $=2971417$

Olkhov, V. (2017d). Business Cycles: Derivation of Equations for Aggregate Fluctuations, Mean Risks and Mean Square Risks. https://ssrn.com/abstract $=3030074$

Olkhov, V. (2017e). Business Cycle Equations. https://ssrn.com/abstract $=3034935$

Pesaran, M.H., Schuermann, T., \& Treutler, B.J. (2007). Global Business Cycles and Credit Risk. in The Risks of Financial Institutions (Ed) Carey, M. and Stulz, R.M. NBER.

Plosser, C.I. (1989). Understanding Real Business Cycles, J. Economic Perspectives, 3, (3), 51-77.

Rebelo, S. (2005). Real Business Cycle Models: Past, Present, And Future. NBER, WP 11401, Cambridge, MA

Resibois, P., \& De Leener, M. (1977). Classical Kinetic Theory of Fluids. John Wiley, NY.

Richter, M., \& Rubinstein, A. (2015). Back to Fundamentals: Equilibrium in Abstract Economies, American Economic Review, 105, (8), 2570-2594.

Schmitt-Grohé, S. \& Uribe, M. (2012). What's News In Business Cycles, Econometrica, 80, (6), 2733-2764.

Schumpeter, J.A. (1939). Business Cycles. A Theoretical, Historical and Statistical Analysis of the Capitalist Process. NY McGraw-Hill Book Company.

Simon, H. A. (1959). Theories of decision-making and behavioral science. The American Economic Review, 49, 253-283.

Skoglund, J., \& Chen, W. (2015). Financial Risk Management: Applications in Market, Credit, Asset and Liability Management, and Firmwide Risk. J.Wiley Sons Inc., US.

Smithies, A. (1957). Economic Fluctuations and Growth. Econometrica. 25, (1), 1-52

Starr, R.M. (2011). General Equilibrium Theory, An Introduction. Camb. Univ. NY

Strauss, W.A. (2008). Partial Differential Equations. An Introduction. John Wiley\&Sons, NJ, US. p.179. 
Tallarini, T.D. (2000). Risk-sensitive real business cycles. J. Monetary Economics, 45, 507-532.

Taylor, J.B. (1984). Rational Expectations and the Business Cycle. Annual Meeting, National Association of Business Economists, Atlanta.

Tesfatsion, L. \& Judd, K. (2005). (Eds.). Handbook of computational economics. Agent-Based Computational Economics. Vol. 2. North-Holland: Elsevier

Thaler, R.H. (2016). Behavioral Economics: Past, Present, and Future. American Economic Review, 106, (7), 15771600 .

Tinbergen, J. (1935). Annual Survey: Suggestions on Quantitative Business Cycle Theory. Econometrica, 3, (3), 241 308.

Zarnowitz, V. (1992). Business Cycles: Theory, History, Indicators, and Forecasting. NBER.

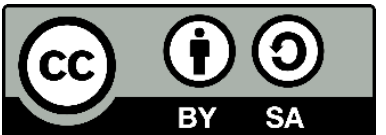

(C) 2019 by the authors. Licensee ACRN Publishing, Austria, Editor in Chief Prof. Dr. Othmar M. Lehner. This article is an open access article distributed under the terms and conditions of the Creative Commons Attribution (CC BY SA) license (https://creativecommons.org/licenses/by-sa/4.0/) 